\section{As pripriocas: seus aromas e suas estruturas}

Por Samuel Soares Almeida

Mestre em Biologia (Ecologia) pelo Instituto Nacional de Pesquisas da Amazônia. Pesquisador Associado do Museu Paraense Emílio Goeldi (samuel@museu-goeldi.br)

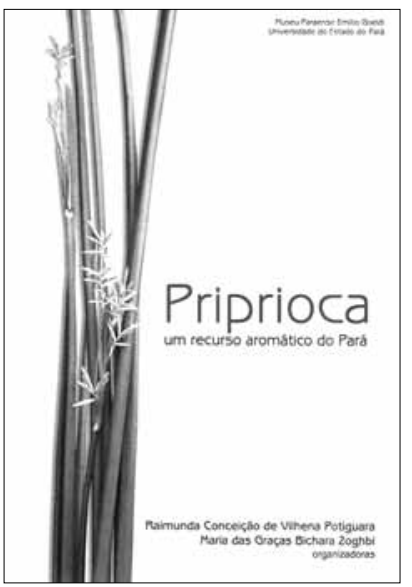

POTYGUARA, Raimunda Conceição de Vilhena; ZOGHBI, Maria das Graças Bichara (Orgs.). Priprioca: um recurso aromático do Pará. Belém: Museu Paraense Emílio Goeldi/ Universidade do Estado do Pará, 2008. 204 p.: il. ISBN 978-85-61377-14-4 (MPEG) e 978-85-88375-31-4

(UEPA).

O livro "Priprioca: um recurso aromático do Pará" foi organizado por Raimunda Conceição de Vilhena Potyguara e Maria das Graças Bichara Zoghbi, da Coordenação de Botânica do Museu Paraense Emílio Goeldi, especialistas em diferentes aspectos da botânica amazônica. A primeira, doutora em Botânica Tropical, atua na investigação da morfologia interna de órgãos e estruturas vegetais de espécies com interesse econômico, tais como plantas fibrosas, alimentícias e aromáticas. A outra organizadora é doutora em Química Orgânica, com atuação em química de produtos naturais, especialmente na prospecção de espécies e identificação de substâncias e estruturas químicas de essências aromáticas, empregadas em perfumes e cosméticos.

A obra é um marco referencial do conhecimento científico e tecnológico sobre a priprioca (Cyperus articulatus L.), uma erva que cresce naturalmente em campos, áreas úmidas e costeiras, sendo também cultivada em pequenas áreas agrícolas, quintais e hortas caseiras. A priprioca é exclusivamente distribuída na
Amazônia, concentrada no leste do estado do Pará, nos baixos cursos dos rios Acará, Moju e Tocantins; parte dos campos inundáveis do arquipélago do Marajó e das microrregiões do Salgado e Bragantina.

A obra é multidisciplinar e seus 12 capítulos podem ser divididos em três grupos de assuntos afins: o primeiro trata de aspectos taxonômicos, morfológicos e de distribuição geográfica. O segundo é direcionado ao entendimento de aspectos químicos e agronômicos, incluindo a propagação da espécie; e o último se refere às cadeias produtiva e comercial, bem como às informações sobre usos e botânica econômica.

Conhecida e comercializada há bastante tempo nas feiras e mercados da região, a priprioca, antes de se tornar de interesse para a indústria de perfumaria, era utilizada em pequena escala na preparação e composição de banhos de cheiro e perfumes artesanais, sendo o 'cheiro-do-pará' o mais requisitado deles, e em sachês e aromatizantes de roupas e armários. A obra reúne informações sobre aspectos cientíícos, tecnológicos e agronômicos recentes, produzidos em instituições científicas e acadêmicas públicas da região. Com ela toma-se conhecimento que a priprioca não é apenas uma espécie, mas pelo menos três - e que os seus rizomas, ou raízes subterrâneas, possuem células oleíferas, secretoras das substâncias aromáticas. A parte química revelou a identidade e as estruturas orgânicas dessas substâncias; suas propriedades alelopáticas, ou o efeito inibidor de seu extrato sobre a germinação de sementes e crescimento de mudas de outras espécies; e, ainda, a ação de contração muscular em cobaias. Os estudos agronômicos recomendam técnicas de cultivo e tratos culturais; propagação vegetativa através dos rizomas; densidade de plantio, produção e produtividade; cadeia produtiva, mercado; e informações sobre outros usos das pripriocas, além do aromático, na medicina tradicional e no artesanato.

A obra representa um avanço considerável para a domesticação da espécie, mas deve-se considerar e creditar que grande parte dos saberes e conhecimentos 
acumulados sobre os usos e o cultivo das pripriocas advém da experiência e das práticas tradicionais de erveiras, mateiros, perfumistas e pequenos produtores. Ainda há um longo caminho a ser percorrido a fim de disponibilizar mais informações sobre o cultivo da espécie, que permitam às pripriocas se constituir num recurso sustentável que possa ser produzido e comercializado numa escala mais abrangente de mercado. 